\title{
Lamivudine-resistant rtL180M and rtM204I/V are persistently dominant during combination rescue therapy with entecavir and adefovir for hepatitis B
}

\author{
YANG WANG $^{1}$, SHUANG LIU $^{1}$, YU CHEN $^{1}$, SUJUN ZHENG ${ }^{1}$, \\ LI ZHOU ${ }^{1}$, FENGMIN LU ${ }^{2}$ and ZHONGPING DUAN ${ }^{1}$ \\ ${ }^{1}$ Artificial Liver Center, Beijing Youan Hospital, Capital Medical University, Beijing 100069; \\ ${ }^{2}$ Department of Microbiology and Infectious Diseases, Peking University Health Science Center, Beijing 100083, P.R. China
}

Received December 18, 2014; Accepted March 14, 2016

DOI: $10.3892 / \mathrm{etm} .2016 .3230$

\begin{abstract}
Adefovir (ADV) sequential monotherapy was included in the 2005 Asia-Pacific guidelines for the management of patients with lamivudine (LAM) resistance. However, following the development of ADV resistance, the proportion of resistant variants during combined rescue therapy with ADV and entecavir (ETV) were unknown. The present study characterized the dynamics of resistant variants in patients with chronic hepatitis B (CHB) and LAM-resistant variants during antiviral therapy consisting of ADV monotherapy followed by ADV-ETV combination therapy. A total of 3 patients were selected from a cohort of 55 patients with $\mathrm{CHB}$ due to developing ADV resistance. The patients had been previously treated with LAM (100 mg daily) for 21-24 months. At the initiation of sequential monotherapy with ADV, LAM-resistant variants (rtM204V/I and rtL180M) were detected in the three patients. These patients developed ADV resistance during 19-30 months of ADV sequential monotherapy, and then switched their antiviral regimen to ADV-ETV combination therapy. During ADV monotherapy and ADV-ETV combination therapy, the patients were monitored every 3 months for the first year of therapy, and then every 6 months thereafter. A total of 30 serum samples were collected from the patients throughout the monitoring period. In total, 10 mutants that were associated with commonly-used antiviral drugs were
\end{abstract}

Correspondence to: Professor Zhongping Duan, Artificial Liver Center, Beijing Youan Hospital, Capital Medical University, 8 Xitoutiao, Youan Menwai Street, Beijing 100069, P.R. China E-mail: duan2517@163.com

Abbreviations: ADV, adefovir; ALT, alanine aminotransferase; $\mathrm{CHB}$, chronic hepatitis B; ETV, entecavir; HBV, hepatitis B virus; LAM, lamivudine; NA, nucleos(t)ide analog; RT, reverse transcriptase

Key words: adefovir, entecavir, hepatitis $\mathrm{B}$ virus, lamivudine resistance, multidrug resistance, rescue therapy detected by pyrosequencing. During ADV sequential monotherapy, LAM-resistant variants were gradually decreased, whereas ADV-resistant rtA181V/T and rtN236T variants gradually increased in the viral population. During 30-41 months of ADV-ETV combination therapy, viral load reduction was 2.59-3.28 $\log _{10}$ copies/ml; ADV-resistant variants $\mathrm{rtA181T/V}$ and rtN236T were undetectable following 11-24 months of combination therapy; and rtL180M and rtM204I/V remained dominant in the viral population. In conclusion, the results of the present study suggested that, in patients with LAM and ADV-resistant variants that developed during LAM-ADV sequential monotherapy, ETV-ADV combination therapy may partially inhibit the replication of HBV DNA; however, LAM-resistant rtL180M and rtM204I/V variants remained predominant following 30-41 months combination therapy.

\section{Introduction}

In total, 240 million individuals are chronically infected with hepatitis B virus (HBV) worldwide (1). Interferon and nucleotide analogs (NAs) are widely used to interrupt the progression of the disease and prevent undesirable clinical outcomes (2). Of these two approaches, NAs are more frequently selected due to their relatively rare side-effects and for patients intolerant of immunomodulatory therapy. However, with long-term NA monotherapy, the selective pressure imposed by the NAs gradually favors an increase in viruses harboring resistant variants to reverse transcriptase (RT), resulting in reduced susceptibility and resistance to NAs $(3,4)$. Virological breakthrough (defined as a confirmed increase in the HBV DNA level by $>1 \log 10$ copies $/ m 1$ compared with the nadir HBV DNA level during therapy), and biochemical breakthrough. may emerge in clinical settings, followed by liver disease progression (5-7).

Lamivudine (LAM)-resistant variants have posed a major challenge in the management of patients with chronic hepatitis B (CHB). Although LAM is not recommended as a first-line therapy in current clinical practice guidelines due to the relatively low genetic barrier to drug resistance, it was the first NA to be developed and has been widely used as a first-line monotherapy drug for 10 years $(8,9)$. Long-term 
LAM monotherapy frequently leads to drug resistance characterized by increased viral replication in patients. The incidence of LAM resistance is $14-32 \%$ after 1 year of treatment, $38 \%$ after 2 years and $53-76 \%$ after 3 years (10). The principal resistant variants associated with LAM resistance are located in domain $\mathrm{C}$ of the YMDD motif (11). These resistant variants include rtM204V, rtM204I and the infrequently identified rtM204S (11-13). The rise of LAM resistance has led to a focus on rescue therapy, which involves switching therapies or using LAM in combination with other NAs. When it initially became available, adefovir (ADV) monotherapy or ADV-LAM combination therapy was used as a rescue therapy following LAM treatment failure for numerous patients with $\mathrm{HBV}$ infection, and these strategies were included in the 2005 Asia-Pacific guidelines for the management of patients with LAM-resistant variants $(8,14)$.

Understanding the dynamics of resistant variants under various antiviral pressures may contribute to improving treatment strategy and preventing undesirable clinical outcomes. The emergence of ADV-resistant variants in patients with LAM resistance was more frequent in patients rescued with ADV monotherapy than patients rescued with LAM-ADV combination therapy (15-17). In rare cases in which LAM and ADV-resistant variants developed during LAM-ADV sequential monotherapy, ADV-entecavir (ETV) was considered as a promising option following previous treatment failure with NAs, where more potent drugs, such as tenofovir (TDF), have not been approved or are not affordable by the majority of the population (18). Based on current knowledge of cross resistance, NAs with an absence of cross-resistance are recommended as rescue regimens in $\mathrm{CHB}$ patients with resistant variants (9). However, to the best of our knowledge, little is known regarding the dynamics of resistant variants of LAM and ADV in patients who sequentially received LAM-ADV monotherapy, and ADV-ETV combination therapy.

In this context, pyrosequencing was used in the present study to investigate the dynamics of LAM-resistant variants during antiviral therapy using ADV sequential monotherapy followed by ADV-ETV combination therapy.

\section{Materials and methods}

Patients. A total of 55 patients with $\mathrm{CHB}$ were enrolled in the present study between June 2007 and July 2008 at the Beijing Youan Hospital, Capital Medical University (Beijing, China). The inclusion criteria were as follows: i) HBsAg positive history for $\geq 6$ months prior to treatment; ii) CHB male or female patients aged $\geq 16$ years; iii) liver function with compensator phase (without ascites, hepatic encephalopathy or upper gastrointestinal bleeding); iv) not pregnant; and v) consent obtained prior to the start of the study. The exclusion criteria were as follows: i) Active liver disease or co-infection with another virus, including hepatitis $\mathrm{C}$, hepatitis $\mathrm{D}$, human immunodeficiency viruses, or the existence of autoimmune liver disease; ii) in addition to hepatitis B, the patient had other major diseases of the organs, such as severe heart disease or kidney disease; iii) renal dysfunction (creatinine clearance $<50 \mathrm{ml} / \mathrm{min}$ ), since it would require that the dosage of the antiviral drug be reduced; iv) poor compliance; v) history of a malignancy, including hepatocellular carcinoma, carcinoma in situ and atypical hyperplastic nodules, life expectancy $<1$ year without liver transplant; vi) patients with mental illness; vii the patients had received corticosteroids, immunosuppressants or chemotherapeutic drugs $\leq 6$ months prior to enrollment; and viii) pregnant and breast-feeding women.

Of the 55 patients, only three with LAM-resistant variants, including one female and two males, developed ADV resistance and were selected for further analysis (Table I). These 3 patients had undergone sequential monotherapy by daily oral administration of $10 \mathrm{mg}$ ADV (GlaxoSmithKline Co., Ltd., Tianjin, China). Following the development of ADV resistance, $0.5 \mathrm{mg}$ ETV (Sino-American Shanghai Squibb Pharmaceutical Ltd., Shanghai, China) was orally administered daily in combination with the ongoing ADV treatment as a rescue therapy. CHB was diagnosed according to the guidelines of the American Association for the Study of Liver Diseases (19) and histology was characterized according to the Ishak scoring system (20). No patient was co-infected with the hepatitis delta virus, hepatitis $\mathrm{C}$ virus, or.

The patients were followed-up from when they started sequential monotherapy with ADV. The patients were consecutively monitored every 3 months in the first year of therapy, and every 6 months thereafter throughout the course of treatment. During each follow-up, serum specimens were collected for liver function tests, viral marker tests, and HBV DNA quantification. Any remaining serum samples were stored at $-80^{\circ} \mathrm{C}$ for subsequent research. There were no reported issues concerning medication non-compliance.

The present study was conducted in compliance with the Declaration of Helsinki (21), and was approved by the Medical Ethics Review Committee of the Beijing Youan Hospital. All patients provided written-informed consent authorizing access to their medical records and storage of the remaining serum specimens for research use.

Measurement of liver function and HBV DNA quantification. Alanine aminotransferase and aspartate aminotransferase levels were measured using an Olympus Automatic Biochemical Analyzer AU5400 (Olympus Corp., Tokyo, Japan) with a cut-off value of $40 \mathrm{IU} / 1$, according to the manufacturer's protocol. The viral markers, including hepatitis B surface antigen (HBsAg), anti-hepatitis B s antibody (HBsAb) hepatitis B e antigen ( $\mathrm{HBeAg}$ ), and anti-hepatitis B e antibody (HBeAb), were determined using commercial chemiluminescence immunoassay kits (cat. nos. S10980090, S10980089, S10980088 and S10980087, respectively; Beijing Wantai Biological Pharmacy Enterprise Co., Ltd., Beijing, China) on an ARCHITECT i-20000SR automatic chemiluminescence immunoassay analyzer (Abbott Laboratories, Chicago, IL, USA). Serum HBV DNA levels were determined using a Cobas HBV Amplicor Monitor assay (Roche Diagnostics, Pleasanton, CA, USA), with a lower limit of detection of $2.46 \log _{10}$ copies $/ \mathrm{ml}$ ( $\sim 50 \mathrm{IU} / \mathrm{ml}$ or 291 copies/ml), according to the manufacturer's protocol.

Detection of antiviral-resistant mutations. The pyrosequencing assay was performed using the PyroMark careHBV Drug Resistance Test kit (Qiagen China Co., Ltd., Shanghai, China) and a PyroMark Q24 MDx system (Qiagen GmbH, Hilden, Germany), according to the manufacturer's protocols. 
Table I. Clinical features of chronic hepatitis B patients with LAM-resistant variants treated with ADV monotherapy followed by ADV-ETV combination therapy.

\begin{tabular}{|c|c|c|c|}
\hline Characteristic & Patient 1 & Patient 2 & Patient 3 \\
\hline Gender & Female & Male & Male \\
\hline Age (years) & 53 & 24 & 45 \\
\hline $\mathrm{HBeAg}$ & + & + & + \\
\hline Duration of LAM (months) & 21 & 24 & 23 \\
\hline LAM-resistant variants & M204I & M204I & $\mathrm{L} 180 \mathrm{M}+\mathrm{M} 204 \mathrm{~V}$ \\
\hline HBV genotype & $\mathrm{C}$ & $\mathrm{C}$ & $\mathrm{C}$ \\
\hline \multicolumn{4}{|l|}{ Viral load } \\
\hline$(\log 10$ copies $/ \mathrm{ml})$ & 6.88 & 6.60 & 8.70 \\
\hline $\operatorname{ALT}(\mathrm{U} / 1)^{\mathrm{a}}$ & 68.5 & 317.3 & 73.6 \\
\hline $\operatorname{AST}(\mathrm{U} / \mathrm{l})^{\mathrm{a}}$ & 64.1 & 81.0 & 35.3 \\
\hline Liver histology (inflammation/fibrosis) ${ }^{\mathrm{b}}$ & $4 / 3$ & $7 / 3$ & $13 / 5$ \\
\hline \multicolumn{4}{|l|}{ During ADV mono-therapy } \\
\hline Duration of ADV(mo) & 19 & 19 & 30 \\
\hline ADV-resistant variants & A181V & $\mathrm{A} 181 \mathrm{~T}$ & N236T \\
\hline \multicolumn{4}{|l|}{ During ADV-ETV combination therapy } \\
\hline Viral load at the start (log 10copies/ml) & 4.04 & 6.21 & 6.01 \\
\hline Duration of ADV-ETV (mo) & 41 & 41 & 30 \\
\hline Liver histology at month 60 (inflammation/fibrosis) $^{\mathrm{b}}$ & $2 / 2$ & $3 / 2$ & $7 / 4$ \\
\hline
\end{tabular}

${ }^{a}$ The upper limit of normal value: ALT, $40 \mathrm{U} / \mathrm{L} ; \mathrm{AST}, 40 \mathrm{U} / \mathrm{L} .{ }^{\mathrm{b}}$ Diagnosed according to Ishak scoring system. LAM, lamivudine; ADV, adefovir; ETV, entecavir; ALT, alanine aminotransferase; AST, aspartate aminotransferase; HBeAg, hepatitis B e antigen; HBV, hepatitis B virus.

HBV DNA purification reagents (silica-gel membrane column and extraction buffers), gene amplification primers, and sequencing primers were included in the kit. The protocol was conducted as previously described (22). A total of 10 mutation sites (rtL169, rtV173, rtL180, rtA181, rtT184, rtA194, rtS202, rtM204, rtN236 and rtM250) were analyzed on the reverse transcription domain of HBV DNA polymerase that were previously reported to be associated with HBV drug resistance (23). In total. 30 samples obtained from three patients were used for detection of these resistant variants.

\section{Results}

Characteristics of patients with LAM-resistant variants at the initiation of sequential monotherapy with $A D V$. The three patients were 24-53 years-old. All patients were treated with $100 \mathrm{mg}$ LAM once daily for 21-24 months. The emergence of LAM-resistant variants, such as rtM204 V/I and/or rtL180 M, was observed in all patients. Their antiviral regimen was switched to ADV monotherapy (10 $\mathrm{mg} /$ day) as a rescue therapy and no patient required a dose reduction. The three patients developed ADV resistance following LAM-ADV sequential monotherapy. The three patients received a percutaneous liver biopsy at initiation of ADV therapy and after 5 years therapy. Their clinical characteristics at the initiation of ADV monotherapy are shown in Table I.

Clinical course of ADV monotherapy followed by ADV-ETV combination therapy. The duration of ADV sequential monotherapy was 19-30 months. After a mean of 10 months (range
6-18 months) monotherapy with ADV, viral load decreased to the lowest level during ADV monotherapy, with an average decrease of $2.60 \log _{10}$ copies/ml (range, 1.28-4.49 $\log _{10}$ copies/ml). Following the passage to ADV-ETV combination therapy, the mean duration of combination therapy was 37.33 months (range, 30-41 months). After a mean duration of 25.33 months (range, 5-41 months) combination therapy, viral load decreased to the lowest level during combination therapy, with an average decrease of $3.0 \log _{10}$ copies $/ \mathrm{ml}$ (range, 2.59-3.28 $\log _{10}$ copies/ml). The clinical course of antiviral therapy in the three patients is shown in Fig. 1.

During the 5 years of therapy, none of the patients exhibited loss of $\mathrm{HBeAg}$ or $\mathrm{HBsAg}$, or had seroconversion to $\mathrm{HBeAb}$ or HBsAb. After 5 years of therapy, the inflammation and fibrosis scores of the liver biopsies were of 4 on average (range, 2-6), and showed a 1 point decrease according to the Ishak scoring system.

Dynamics of LAM-resistant variants during ADV monotherapy followed by ADV-ETV combination therapy. The three patients had LAM-resistant variants (rtM204I/V with or without rtL180 M) at the initiation of sequential ADV monotherapy (Fig. 2). During sequential monotherapy, the levels of LAM-resistant variants (rtM204I/V with or without rtL180 M) gradually decreased as treatment progressed, whereas ADV-resistant rtA181 V/T and rtN236T gradually increased and became dominant in the viral populations (Fig. 2). Following passage to an ADV-ETV combination regimen, ADV-resistant rtA181 V/T and rtN236T gradually decreased and became undetected in the viral population, whereas LAM-resistant variant 

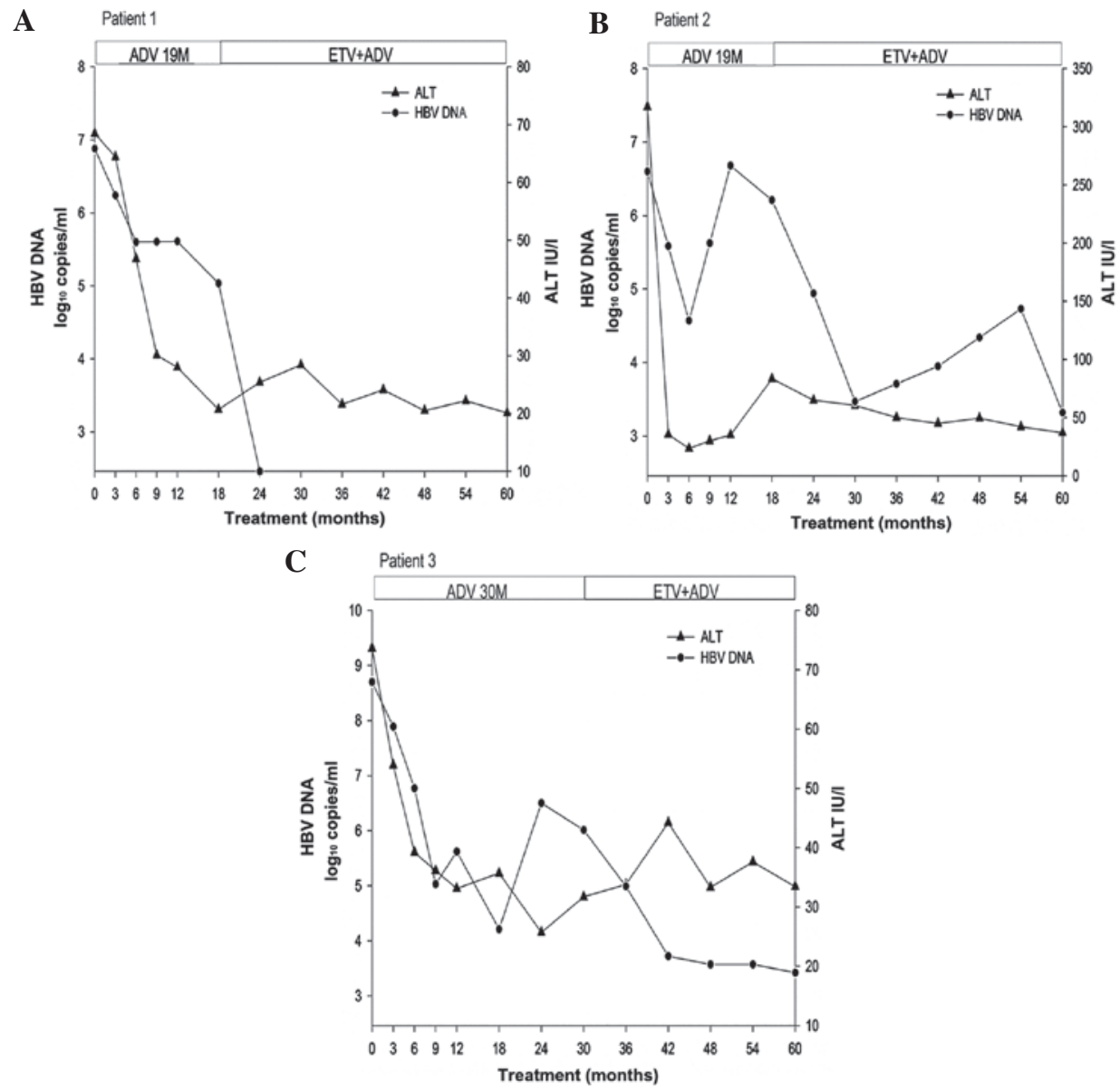

Figure 1. Clinical course of ADV monotherapy followed by ADV-ETV combination therapy in patients with LAM resistance. (A) Virological and biochemical breakthroughs were not detected in patient 1 during the treatment course; whereas the biochemical breakthrough lagged behind the virological breakthrough in patients (B) 2 and (C) 3. HBV, hepatitis B virus; ADV, adefovir; ETV, entecavir; ALT, alanine aminotransferase.

(rtM204I/V with or without rtL180 M) was dominant in the viral population during combination therapy (Fig. 2). ADV-resistant variants rtA181 V/T and rtN236T went from being dominant at initiation of ADV-ETV combination to undetectable, during an average duration of combination therapy of 19.33 months (range, 11-24 months) (Fig. 2). After a mean of 37.33 months (range, 30-41 months) combination treatment, LAM-resistant variants (rtM204I/V with or without rtL180 M) remained dominant in the viral population (Fig. 2).

The dynamics of resistant variants in the three patients in whom the pyrosequencing analyses were performed during the sequential antiviral treatment are illustrated in Fig. 2. In Patient 1, in addition to rtM204I, the serum sample taken at the initiation of sequential ADV monotherapy harbored ADV-resistant rtA181 V. This resistant variant existed as a minor subpopulation and in $<10 \%$ of the viral population. ETV was administered after 19 months of monotherapy, and resistant rtA181 V gradually decreased and became undetectable after 11 months of combination therapy. In Patient 2, resistant rtA181T was rapidly selected and accompanied by virological breakthrough following 12 months of ADV monotherapy. ADV-resistant variant rtA181T then decreased and became undetected after 23 months of combination therapy. The dynamics of resistant variants was characterized by successive waves, with the rtM204I variant being initially dominant, then being replaced by the rtA181T variant, and finally, by the
rtL180 M and rtM204 V variants. The biochemical breakthrough coincided with the shift from dominant rtM204I to dominant rtA181T after 18 months. In Patient 3, the viral load of the virus harboring rtN236T gradually increased for 6 months prior to virological breakthrough. The resistant variant rtN236T became dominant and accompanied by virological breakthrough after 24 months. ADV-resistant variant rtN236T decreased and became undetected following 2 years of combination therapy. In contrast to Patient 2, dominant resistant variants rtL180 M and rtM204 V were replaced by dominant variant $\mathrm{rtN} 236 \mathrm{~T}$ following sequential ADV monotherapy, and were then replaced by dominant variants rtL180 M and rtM204 V during ADV-ETV combination therapy.

\section{Discussion}

Therapeutic regimens for the treatment of CHB have evolved rapidly over the past few years $(8,9)$. Prolonged monotherapy with LAM is associated with the emergence of LAM-resistant variants and the progression of liver disease (9,24,25). ADV sequential monotherapy as a rescue regimen was included in the 2005 Asia-Pacific consensus and guidelines for the management of patients with LAM-resistant variants (8). Subsequent studies have suggested that sequential NA monotherapy could promote the selection of multidrug-resistant variants $(17,26)$, but little is known with regard to the dynamics of these resistant 
A

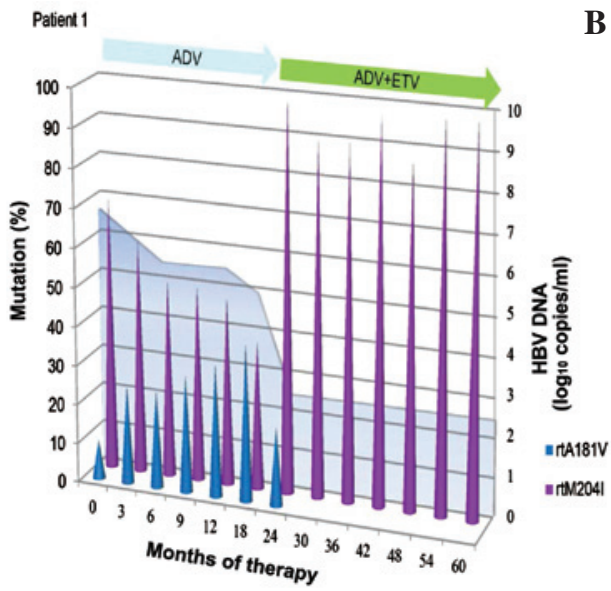

B Patent2

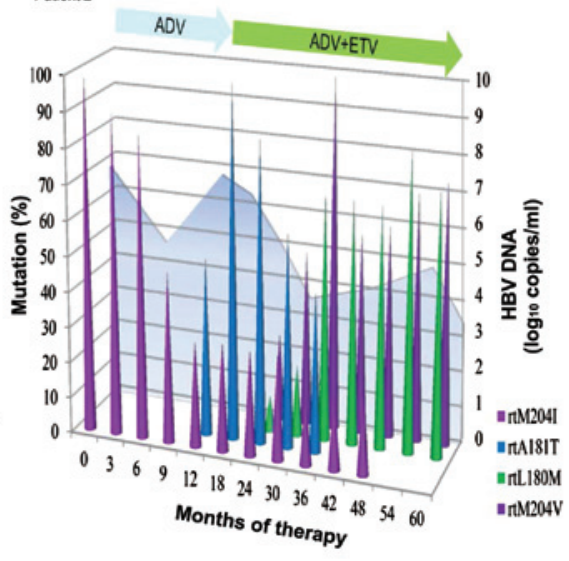

C

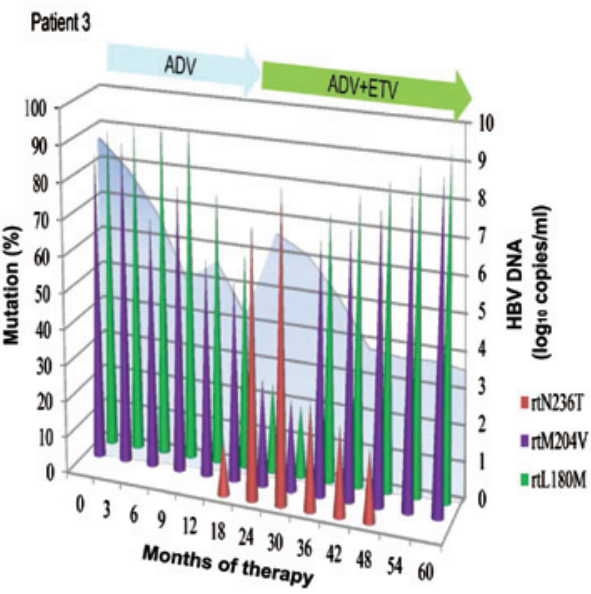

Figure 2. Dynamics of resistant variants during ADV monotherapy followed by ADV-ETV combination therapy in patients with LAM resistance. (A) The levels of LAM-resistant rtM204I variant gradually decreased during ADV monotherapy, whereas it became dominant during ADV-ETV combination therapy. (B) The initially dominant rtM204I variant was replaced by the rtA181T variant, and finally, by the rtL180M and rtM204V variants. (C) Dominant resistant variants rtL180M and rtM204V were replaced by dominant variant rtN236T following sequential ADV monotherapy, and were then replaced by dominant variants rtL180M and rtM204V during ADV-ETV combination therapy. HBV, hepatitis B virus; ADV, adefovir; ETV, entecavir; LAM, lamivudine.

variants during ADV-ETV combination therapy. In the present longitudinal study, pyrosequencing was used to characterize the dynamics of resistant variants in patients with LAM resistance during ADV monotherapy followed by ADV-ETV combination therapy. The results of the present study demonstrated that replication of ADV-resistant variants, rtA181T/V and rtN236T, was inhibited by combination therapy with ADV-ETV, whereas LAM-resistant rtL180 M and rtM204I/V were persistent during 30-41 months of combination therapy. Therefore, the results strongly suggest that LAM should be carefully prescribed for NA-naïve patients, due to the intractable issues following the emergence of resistant variants.

Treatment of CHB patients with resistant variants remains a complex topic. In NAs-naïve patients, it has been reported that the cumulative rate of ADV resistance was 0,11 and $28 \%$ at 1,3 and 5 years, respectively (17). In patients with LAM-resistant variants, following sequential monotherapy with $\mathrm{ADV}$, the cumulative rate of ADV resistance was 18 and $25 \%$ after 1 and 2 years, respectively $(17,26)$. As for the outcome of the rescue strategy, ADV-LAM combination therapy is more effective in reducing viral load than switching to ADV monotherapy in patients with LAM-resistant variants (27-31), However, previous longitudinal studies $(6,24,25,32)$ demonstrated that the replication of LAM-resistant variants was not fully inhibited by ADV monotherapy or LAM-ADV combination therapy. These results may be attributed to an ADV-resistant variant, rtA181 V/T, which is responsible for cross-resistance to $\operatorname{LAM}$ and ADV $(11,32,33)$. A previous study reported that LAM-resistant variants, rtM204I/V and rtL180 M, were suppressed, but ADV-resistant variant $\mathrm{rtA} 181 \mathrm{~V} / \mathrm{T}$ emerged after 13-19 months of LAM-ADV sequential monotherapy (25). In the present study, the data demonstrated that LAM-resistant variants rtL180 M and rtM204I/M were suppressed, whereas ADV-resistant variant rtA181 V/T or rtN236T was increased in patients with LAM resistance during 19-30 months of ADV sequential monotherapy. These results were concordant with earlier findings from a previous study that determined that LAM-resistant variants (rtM204I/V and rtL180 M) decreased whereas ADV-resistant variants gradually increased during ADV monotherapy (24). ADV suppression of LAM-resistant variants, mainly due to $\mathrm{rtL} 180 \mathrm{M}$ and $\mathrm{rtM} 204 \mathrm{I} / \mathrm{M}$, does not significantly affect sensitivity to ADV.

Data regarding the therapeutic regimen for patients with LAM and ADV resistance remain limited (11,24,25,32,34). In patients who have failed sequential LAM-ADV treatment, one recent study reported that combination therapy with 
ETV-ADV was more effective at reducing viral load compared with ADV-LAM combination therapy and ETV monotherapy, but the difference was not significant (35). Another recent study reported that TDF-ETV is a potent therapeutic option for patients with LAM and ADV resistance, and the cumulative probability of virological suppression at 6 months was $75.0 \%$ in 28 patients (36). However, the efficacy and safety profiles of these regimens were not well compared, therefore, to date, the optimal treatment option for patients with LAM and ADV resistance has not been identified. It has been reported (25) that LAM-ADV combination therapy may not suppress the LAM and ADV-resistant variants that emerge during LAM-ADV sequential monotherapy. In the present study, regardless of the presence of LAM-resistant variants, it was observed that the replication of ADV-resistant variants rtA181 V and/or rtN236T was inhibited after 11-24 months of ADV-ETV combination therapy. A resistant variant becoming undetectable is considered to be a good response to rescue therapy $(11,22,24,32,34,37)$. However, previous studies have suggested that undetectable resistant variants may be a transition phase in the selective process of novel drug-resistant variants $(34,38)$.

It should be noted that, even when the viral load decreases following the addition of ETV to ongoing ADV therapy, LAM-resistant variants $\mathrm{rtL} 180 \mathrm{M}$ and $\mathrm{rtM} 204 \mathrm{I} / \mathrm{V}$ persist after 30-41 months of ADV-ETV combination therapy. This result may be predictable as rtM204 V results in partial cross resistance to LAM and ETV $(22,23,37)$. However, it was demonstrated that LAM-resistant variants were persistently dominant during ADV-ETV combination therapy in a clinical study. Second, persistence of LAM-resistant variants rtL180 $\mathrm{M}$ and rtM204 V increases the risk of ETV resistance, and therefore a more potent antiviral regimen, such as TDF-ETV combination therapy, may be considered in these rare cases. Conversely, for patients with ETV resistance, physicians need to inquire repeatedly about past medication history. Third, histological benefits in the patients may be somewhat affected by the emergence of drug-resistant variants during antiviral therapy. In the present study, all patients exhibited an improvement in inflammation scores and none of the patients showed progression of fibrosis. The results suggest that ADV-ETV combination rescue therapy may contribute to histological improvement. Whether ADV-resistant variants re-emerge, or ETV-resistant variants (rtT184, rtS202 or rtM250) are selected in these patients warrants further investigation.

Although sensitive pyrosequencing was used in the present study to detect an average of 10 time-point serum samples for $\leq 5$ years of treatment, the study presented certain limitations, including the small number of patients and absence of treatment failure during the short duration of combination therapy with ADV-ETV. These limitations may make ADV-ETV combination an inappropriate rescue therapy for patients with resistance to LAM and ADV. To verify the efficacy and phenomenon of this salvage regimen, further large cohort studies are needed.

In conclusion, following LAM-ADV sequential monotherapy failure, ADV-ETV combination therapy partially inhibited replication of HBV DNA in patients with LAM and ADV resistance, as demonstrated by the decreased
HBV DNA levels and inhibition of ADV-resistant variants. However, LAM-resistant rtL180 M and rtM204I/V remained predominant during the 30-41 months of ADV-ETV combination therapy. These results may be attributed to the resistant variants that are responsible for some of the cross-resistance to LAM and ETV. Therefore, careful monitoring and more potent antiviral regimens should be considered in CHB patients with multidrug resistance.

\section{Acknowledgements}

The present study was funded by grants from the National Science and Technology Key Project (grant nos. 2012ZX10002004-006, 2012ZX10004904-003-001, 2013ZX10002002-006 and 2012ZX10002005); the Ministry of Science and Technology of China (grant no. 2012ZX09301002-006); the High Technical Personnel Training Item of the Beijing Health System (grant nos. 2011-3-083 and 2013-3-071); the Beijing Municipal Science \& Technology Commission (grant no. Z131107002213019); the Clinical Medicine Development Special Fund, Beijing Municipal Administration of Hospitals (grant no. XM201308); and the National Key Subject Construction Project (grant no. WJWYA-2014-002).

\section{References}

1. Ott JJ, Stevens GA, Groeger J and Wiersma ST: Global epidemiology of hepatitis B virus infection: New estimates of age-specific HBsAg seroprevalence and endemicity. Vaccine 30: 2212-2219, 2012.

2. Peng CY, Chien RN and Liaw YF: Hepatitis B virus-related decompensated liver cirrhosis: Benefits of antiviral therapy. J Hepatol 57: 442-450, 2012.

3. Buti M: HBeAg-positive chronic hepatitis B: Why do i treat my patients with Nucleos(t)ide analogs? Liver Int 34 Suppl 1: 108-111, 2014.

4. Viganò $\mathrm{M}$, Mangia $\mathrm{G}$ and Lampertico P: HBeAg-negative chronic hepatitis B: Why do I treat my patients with nucleos(t)ide analogues? Liver Int 34 Suppl 1: 120-126, 2014.

5. Yuen MF, Sablon E, Hui CK, Yuan HJ, Decraemer H and Lai CL: Factors associated with hepatitis B virus DNA breakthrough in patients receiving prolonged lamivudine therapy. Hepatology 34 : 785-791, 2001.

6. Rodriguez C, Chevaliez S, Bensadoun P and Pawlotsky JM: Characterization of the dynamics of hepatitis B virus resistance to adefovir by ultra-deep pyrosequencing. Hepatology 58: 890-901, 2013.

7. Zoulim F and Locarnini S: Hepatitis B virus resistance to nucleos $(\mathrm{t})$ ide analogues. Gastroenterology 137: 1593-1608; e1591-1592, 2009.

8. Liaw YF, Leung N, Guan R, Lau GK, Merican I, McCaughan G, Gane E, Kao JH and Omata M; Asian-Pacific consensus update working party on chronic hepatitis B: Asian-Pacific consensus statement on the management of chronic hepatitis B: A 2005 update. Liver Int 25: 472-489, 2005.

9. Liaw YF, Kao JH, Piratvisuth T, Chan HL, Chien RN, Liu CJ, Gane E, Locarnini S, Lim SG, Han KH, et al: Asian-Pacific consensus statement on the management of chronic hepatitis B: A 2012 update. Hepatol Int 6: 531-561, 2012.

10. Lai CL, Dienstag J, Schiff E, Leung NW, Atkins M, Hunt C, Brown N, Woessner M, Boehme R and Condreay L: Prevalence and clinical correlates of YMDD variants during lamivudine therapy for patients with chronic hepatitis B. Clin Infect Dis 36: 687-696, 2003.

11. Pallier C, Castéra L, Soulier A, Hézode C, Nordmann P, Dhumeaux D and Pawlotsky JM: Dynamics of hepatitis B virus resistance to lamivudine. J Virol 80: 643-653, 2006.

12. Bozdayi AM, Uzunalimoğlu O, Türkyilmaz AR, Aslan N, Sezgin O, Sahin T, Bozdayi G, Cinar K, Pai SB, Pai R, et al: YSDD: A novel mutation in HBV DNA polymerase confers clinical resistance to lamivudine. J Viral Hepat 10: 256-265, 2003. 
13. Niesters HG, De Man RA, Pas SD, Fries E and Osterhaus AD: Identification of a new variant in the YMDD motif of the hepatitis $\mathrm{B}$ virus polymerase gene selected during lamivudine therapy. J Med Microbiol 51: 695-699, 2002

14. Liaw YF, Lee CM, Chien RN and Yeh CT: Switching to adefovir monotherapy after emergence of lamivudine-resistant mutations in patients with liver cirrhosis. J Viral Hepat 13: 250-255, 2006.

15. Zhao P, Wang C, Huang L, Xu D and Li T: Comparison of rescue strategies in lamivudine-resistant patients with chronic hepatitis B. Antiviral Res 96: 100-104, 2012.

16. Vassiliadis TG, Giouleme O, Koumerkeridis G, Koumaras H, Tziomalos K, Patsiaoura K, Grammatikos N, Mpoumponaris A, Gkisakis D, Theodoropoulos K, et al: Adefovir plus lamivudine are more effective than adefovir alone in lamivudine-resistant HBeAg- chronic hepatitis B patients: A 4-year study. J Gastroenterol Hepatol 25: 54-60, 2010.

17. Lee YS, Suh DJ, Lim YS, Jung SW, Kim KM, Lee HC, Chung YH, Lee YS, Yoo W and Kim SO: Increased risk of adefovir resistance in patients with lamivudine-resistant chronic hepatitis B after 48 weeks of adefovir dipivoxil monotherapy. Hepatology 43: 1385-1391, 2006.

18. Kang SH, Yim HJ, Kim HR, Kang K, Suh SJ, Lee HJ, Yoon EL, Kim JH, Seo YS, Yeon JE and Byun KS: Comparison of lamivudine plus adefovir therapy versus entecavir with or without adefovir therapy for adefovir-resistant chronic hepatitis B. J Clin Gastroenterol 48: 889-895, 2014.

19. Lok AS and McMahon BJ: Chronic hepatitis B. Hepatology 45 : 507-539, 2007

20. Goodman ZD: Grading and staging systems for inflammation and fibrosis in chronic liver diseases. J Hepatol 47: 598-607, 2007

21. World Medical Association: World Medical Association Declaration of Helsinki: Ethical Principles for Medical Research Involving Human Subjects. JAMA 310: 2191-2194, 2013.

22. Lee GH, Inoue M, Toh JK, Chong RH, Aung MO, Koay ES and Lim SG: Two-step evolution of the hepatitis B drug-resistant mutations in a patient who developed primary entecavir resistance. Liver Int 33: 642-646, 2013.

23. Lok AS, Zoulim F, Locarnini S, Bartholomeusz A, Ghany MG Pawlotsky JM, Liaw YF, Mizokami M and Kuiken C; Hepatitis B Virus Drug Resistance Working Group: Antiviral drug-resistant HBV: Standardization of nomenclature and assays and recommendations for management. Hepatology 46 254-265, 2007.

24. Ijaz S, Arnold C, Dervisevic S, Mechurova J, Tatman N, Tedder RS and Naoumov NV: Dynamics of lamivudine-resistant hepatitis B virus during adefovir monotherapy versus lamivudine plus adefovir combination therapy. J Med Virol 80: 1160-1170, 2008.

25. Ko SY, Kim BK, Kwon SY, Kim KH, Kim JH, Choe WH and Lee $\mathrm{CH}$ : Clonal evolution of hepatitis B virus polymerase gene mutations during lamivudine-adefovir combination treatment. World J Gastroenterol 18: 6437-6446; discussion p 6445, 2012
26. Yeon JE, Yoo W, Hong SP, Chang YJ, Yu SK, Kim JH, Seo YS, Chung HJ, Moon MS, Kim SO, et al: Resistance to adefovir dipivoxil in lamivudine resistant chronic hepatitis B patients treated with adefovir dipivoxil. Gut 55: 1488-1495, 2006.

27. Lee SJ, Yim HJ, Hwang SG, Seo YS, Kim JH, Yoon EL, Lee JM, Kim BH, Park SJ, Park YM, et al: Treatment of lamivudine-resistant chronic hepatitis B infection: A multicenter retrospective study. Scand J Gastroenterol 48: 196-204, 2013

28. Yim HJ, Seo YS, Yoon EL, Kim CW, Lee CD, Park SH, Lee MS, Park CK, Chae HB, Kim MY, et al: Adding adefovir vs. switching to entecavir for lamivudine-resistant chronic hepatitis B (ACE study): A 2-year follow-up randomized controlled trial. Liver Int 33: 244-254, 2013

29. Wang M, Yuan L, Qiao B and Li Y: Two rescue therapies in lamivudine-resistant patients with chronic hepatitis B in the central China: Adefovir monotherapy and adefovir plus lamivudine. Virus Genes 48: 32-37, 2014.

30. Huang ZB, Zhao SS, Huang Y, Dai XH, Zhou RR, Yi PP, Chen RC, Li WT, Zhang BX, Li N and Fan XG: Comparison of the efficacy of Lamivudine plus adefovir versus entecavir in the treatment of Lamivudine-resistant chronic hepatitis B: A systematic review and meta-analysis. Clin Ther 35: 1997-2006, 2013.

31. Kim HJ, Park JH, Park DI, Cho YK, Sohn CI, Jeon WK and Kim BI: Rescue therapy for lamivudine-resistant chronic hepatitis B: Comparison between entecavir $1.0 \mathrm{mg}$ monotherapy, adefovir monotherapy and adefovir add-on lamivudine combination therapy. J Gastroenterol Hepatol 25: 1374-1380, 2010.

32. Pallier C, Rodriguez C, Brillet R, Nordmann P, Hézode C and Pawlotsky JM: Complex dynamics of hepatitis B virus resistance to adefovir. Hepatology 49: 50-59, 2009.

33. Villet S, Pichoud C, Billioud G, Barraud L, Durantel S, Trépo C and Zoulim F: Impact of hepatitis B virus rtA181V/T mutants on hepatitis B treatment failure. J Hepatol 48: 747-755, 2008.

34. Deng XL, Li QL and Guo JJ: Dynamics of lamivudine-resistant hepatitis B virus strains in patients with entecavir rescue therapy. Virus Genes 47: 1-9, 2013.

35. Park MS, Kim BK, Kim KS, Kim JK, Kim SU, Park JY, Kim do Y, Baartarkhuu O, Han KH, Chon CY and Ahn SH: Antiviral efficacies of currently available rescue therapies for multidrug-resistant chronic hepatitis B. Clin Mol Hepatol 19: 29-35, 2013.

36. Lee YB,Lee JH,Lee DH, Cho H, Ahn H, Choi WM, Cho YY,LeeM, Yoo JJ, Cho Y, et al: Efficacy of entecavir-tenofovir combination therapy for chronic hepatitis B patients with multidrug-resistant strains. Antimicrob Agents Chemother 58: 6710-6716, 2014.

37. Villet S, Ollivet A, Pichoud C, Barraud L, Villeneuve JP Trépo C and Zoulim F: Stepwise process for the development of entecavir resistance in a chronic hepatitis B virus infected patient. J Hepatol 46: 531-538, 2007.

38. Villeneuve JP, Durantel D, Durantel S, Westland C, Xiong S, Brosgart CL, Gibbs CS, Parvaz P, Werle B, Trépo C and Zoulim F: Selection of a hepatitis B virus strain resistant to adefovir in a liver transplantation patient. J Hepatol 39: 1085-1089, 2003. 